\title{
Chagas Disease and Human Migration
}

\section{Felipe Guhl ${ }^{+}$, Carlos Jaramillo*, Gustavo A Vallejo**, Felipe Cárdenas A-Arroyo***, Arthur Aufderheide**}

\author{
Centro de Investigaciones en Microbiología y Parasitología Tropical, Universidad de los Andes, Apartado Aereo \\ 4976, Bogotá, Colombia *Departamento de Biología, Facultad d Ciencias, Universidad del Tolima, Ibagué, \\ Colombia **Paleobiology Laboratory, School of Medicine, University of Minnesota, Duluth, Minnesota, USA \\ ***Departamento de Antropología, Universidad de los Andes, Bogotá, Colombia
}

Human Chagas disease is a purely accidental occurrence. As humans came into contact with the natural foci of infection might then have become infected as a single addition to the already extensive host range of Trypanosoma cruzi that includes other primates. Thus began a process of adaptation and domiciliation to human habitations through which the vectors had direct access to abundant food as well as protection from climatic changes and predators.

Our work deals with the extraction and specific amplification by polymerase chain reaction of $\mathrm{T}$. cruzi DNA obtained from mummified human tissues and the positive diagnosis of Chagas disease in a series of 4,000-year-old Pre-Hispanic human mummies from the northern coast of Chile.

The area has been inhabited at least for 7,000 years, first by hunters, fishers and gatherers, and then gradually by more permanent settlements. The studied specimens belonged to the Chinchorro culture, a people inhabiting the area now occupied by the modern city of Arica. These were essentially fishers with a complex religious ideology, which accounts for the preservation of their dead in the way of mummified bodies, further enhanced by the extremely dry conditions of the desert. Chinchorro mummies are, perhaps, the oldest preserved bodies known to date.

Key words: palaeoparasitology - Trypanosoma cruzi - mummies - human migration

The epidemiological pattern of Trypanosoma cruzi reveals that primitive transmission was restricted to specific cycles in tropical forest environments, where triatomine insects would feed on small mammals in broad areas of the South American continent, without humans intervening in the natural cycle. The same situation persists today in wild areas configuring a wild enzootic epidemiological character. The presence of $T$. cruzi does not seem to affect triatomines significantly nor the mammals which have been naturally infected. This would suggest a balance between species as a result of long periods of adaptation (Guhl et al. 1999).

Although in general the Hemiptera represent an ancient order, with fossilized remains dating from the Permian (nearly 232-280 m.ya), it is possible that the evolution of triatomines correspond to a series of later events starting at different times and from diverse ancestral forms (Schofield 1994).

${ }^{+}$Corresponding author. Fax: +571-3324540. E-mail: fguhl@uniandes.edu.co

Received 13 April 2000

Accepted 15 May 2000
The Hemiptera comprise a large order with over 80,000 widely distributed species in all tropical and temperate areas.

Ancestral predatory habits among the triatomines can be inferred by the fact that some species occupy a relatively wide spectrum of ecotopes and are able to exploit different species of hosts. Others on the contrary, occupy restricted habitats and hosts (Schofield \& Matthews 1985).

The vectorial transmission of T. cruzi is restricted to the New World. The geographic distribution of triatomine species extends from the Neotropical to the Neoartic regions. The most frequent triatomine in the Southern Cone of South America is Triatoma infestans, usually found in rural dwellings inside the cracks of walls and roofs.

The origin and spread of humans coincided with the latter part of the Pleistocene ice ages, and the geographical distribution of early humans was influenced by these ice ages in a number of ways.

Archaeological excavations have been carried out along the Aleutian Islands chain, the west coasts of Canada and the United States, as well as in the west coasts of Central and South America. All yield evidence for the presence of human activity since nearly 15,000 years ago. However, the precise date for human presence in the continent may be even earlier, as far back as 20 to 25 thousand 
years, although this evidence is still a matter of debate among archaeologists. For the purpose of our study, it is safe to conclude that humans were spreading south and east of North America and that these small bands of hunter and gatherers had reached the northern tip of South America around 12 to 10 thousand years ago.

Such an amount of time was enough for the adaptation of various parasitic diseases to their new hosts. Cultural developments, such as agriculture and permanent or semi-permanent settlement patterns, created an ideal environment for the spread of infectious diseases, such as tuberculosis and syphilis. Human cultural adaptation to warm and humid environments, allowed for the widespread of Chagas disease.

The epidemiological pattern of $T$. cruzi reveals that primitive transmission was restricted to specific cycles in tropical forest environments, where initially the parasite was spread via anal gland secretions and urine from opossums and later via triatomine insects that would feed on small mammals in broad areas of the South American continent, without humans intervening in this natural cycle. This would suggest a balance between species as a result of long periods of adaptation. The same situation persists today in wild areas configuring a wild enzootic epidemiological character. The presence of $T$. cruzi does not seem to affect triatomines significantly nor the mammals which have been naturally infected. Humans might then have become infected as a single addition to the already extensive host range of $T$. cruzi that includes other primates (Figure; Hoare 1972). Human Chagas disease is a purely accidental occurrence. As humans came into contact with the natural foci of infection and caused different degrees of ecological transformations, infected triatomine insects were forced to occupy their dwellings. Thus began a process of adaptation and domiciliation to human habitations through which the vectors had direct access to abundant food as well as protection from climatic changes and predators. A good example of this is $T$. infestans the main vector of $T$. cruzi in the southern cone countries in America which is considered an almost exclusively domiciliary specie.

A few authors have dedicated their efforts to the identification of $T$. cruzi in mummified human tissues through the application of immunochemical and electron microscope (EM) techniques. Fornaciari et al. (1992) reported the infection of human tissue by $T$. cruzi in a Peruvian Inca mummy using these methods. Furthemore, gross morphopathological evidence for the presence of prehistoric Chagas disease diagnosed from anatomic pathological changes (mega syndromes) in ancient Chilean mummies has been presented by

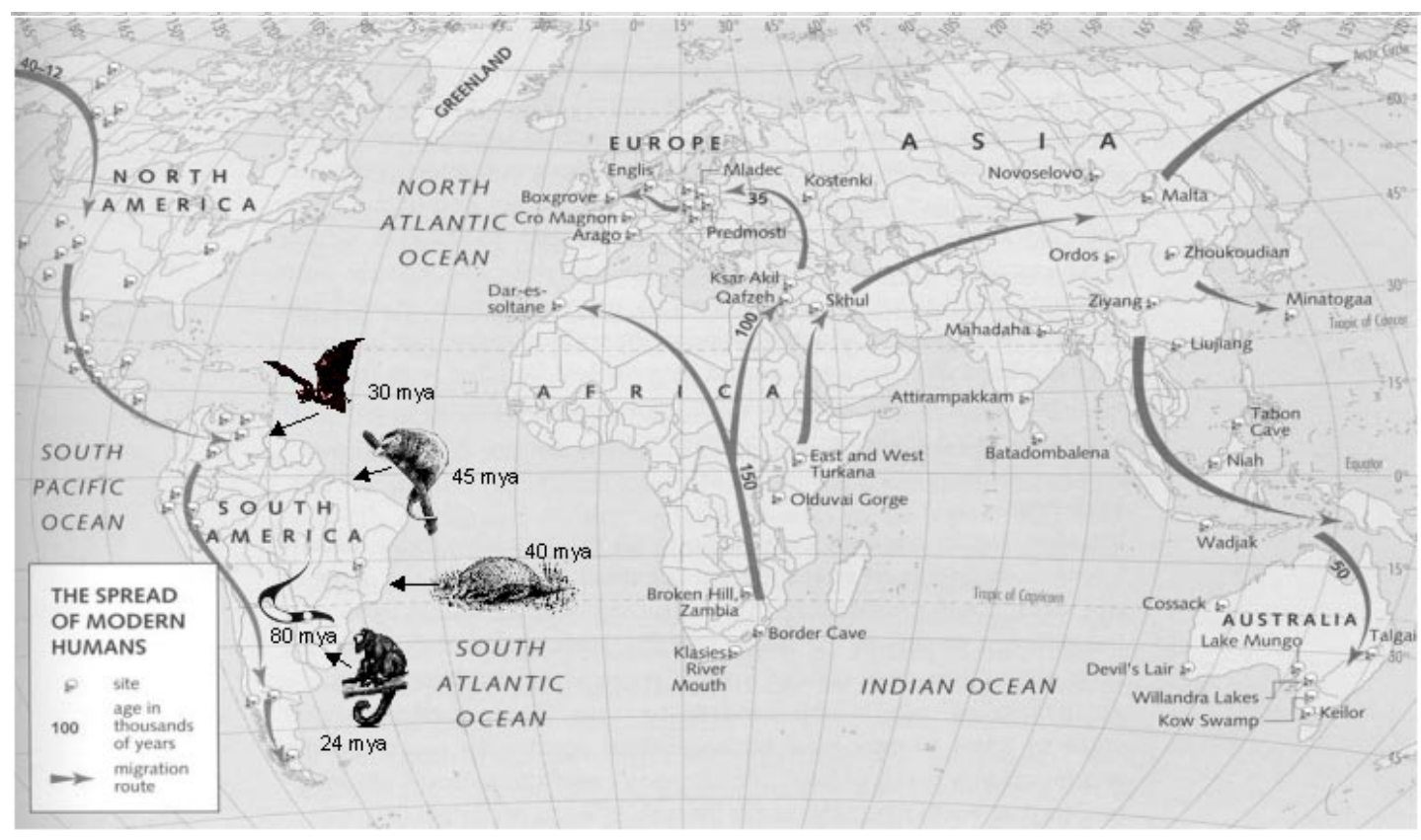

Chagas disease in mummified remains. Migration routes and spread of modern humans. Hypothesized evolutionary sylvatic cycle of Trypanosoma cruzi in America. Human contact with T. cruzi occurred as a simple addition to the already extensive host range around 8-10 thousands years ago. 
Rothhammer et al. (1985) with radiocarbon dates ranging between $470 \mathrm{BC}$ to $600 \mathrm{AD}$. Associated cultural contexts indicated the presence of mud brick dwellings, these being a common habitat for triatomines.

The detection of organic compounds in ancient remains has opened a new research area with many implications, the most important being the extraction of ancient DNA (aDNA) from fossils, biological sources, bone and mummified human bodies.

Origin of the samples - Atacama Desert in Chile is one of the driest places on earth. This sandy region lies between the Andes Mountains and the Pacific coast of Chile. To the north, the Atacama spans the southernmost border of Peru.

Nearby residents have used the desert as a burial ground for thousands of years. Peruvian and Chilean Indians usually buried their dead in shallow pits dug into the surface of the desert. The dry heat desiccated the soft tissue and preserved the bodies. The oldest mummy found in the Atacama is about 9,000 years old, who constitutes the oldest mummified human remains on earth.

The Chinchorro people initiated coastal colonization of river mouths about 7,500 $\mathrm{BC}$ and practiced a maritime economy until 1,500 BC.

Egyptian mummies are quite different from the Atacama ancients. In most cases, the Chinchorro Indians relied on the heat of the desert to mummify their dead.

\section{MATERIALS AND METHODS}

Different tissue samples were obtained from 27 spontaneously mummified bodies by anatomic dissection. Specimens were acquired by dissections in communities near the site and kept in waterproof and airtight containers until analysis.

Tissues from heart, lung, esophagus, stomach and colon were obtained.

Tissue samples from a Peruvian Inca adult female mummy in whose tissues EM and immunostaining had identified $T$. cruzi amastigotes (Fornaciari et al. 1992) were used as positive control.

Similarly, tissues from a spontaneously mummified ancient Egyptian body (about 200 AD) from Dakhleh Oasis were included as a negative control.

Following the strategy described by Avila et al. (1991) we rehydrated the ancient tissues from all 27 bodies and extracted DNA in order to amplify by (PCR) the target of 330 base-pair segment using primers S35 and S36 which anneal in the multiple repeat minicircle DNA segments from the kinetoplast of T. cruzi.
Sample extracts of human mummy tissues were prepared similar to methods described by Salo et al. (1994) and amplified by PCR with primers S35 and S36.

A positive test was described as the isolation of a $330 \mathrm{bp}$ band on gel electrophoresis. Mummies had positive tests on at least one sample.

Seven of 27 heart samples, and four of four esophagus samples tested were positive. One mummy had positive reaction in samples of heart, esophagus, colon and rectum but negative result in iliac and lung sample.

Brazilian workers infected a mouse with T. cruzi, killed and dehydrated it (Bastos et al. 1996). After rehydration of a sample they were able to recover the same DNA target we sought. Our results indicate that human residents at coastal sites in southwestern South America suffered from American trypanosomiasis as long as 4,000 years ago (Guhl et al. 1997).

\section{ACKNOWLEDGEMENTS}

To Sandra Molina, Juan Manuel Cordovéz, Enrique Villarraga and Carlos Mejía who have contributed to this article by providing materials or ideas.

\section{REFERENCES}

Bastos OM, Araujo A, Ferreira LF, Santoro A, Winckler P, Morel CA 1996. Experimental paleoparasitology identification of Trypanosoma cruzi in desiccated mouse tissue. Paleopath Newsletter (Detroit) 94: 5-8.

Fornaciari G, Castagna M, Viacava P, Togneti A, Bevilaqua G, Segura EL 1992. Chagas disease in Peruvian Inca mummy. Lancet 339: 128-129.

Guhl F, Jaramillo C, Vallejo GA, Yockteng R, CárdenasArroyo F, Fornaciari G, Arriaza B, Aufderheide A 1999. Isolation of Trypanosoma cruzi DNA in a 4,000 year-old mummified human from northern Chile. $\mathrm{Am}$ J Phy Anthropol 108: 401-407.

Guhl F, Jaramillo C, Yockteng R, Cárdenas-Arroyo F 1997. Trypanosoma cruzi DNA in human mummies. Lancet 349: 1370.

Hoare CA 1972. The Trypanosomes of Mammals, Blackwell Scientific Publications, UK.

Rothhammer F, Allison MJ, Núñez L, Staden V, Arriaza B 1985.Chagas disease in pre Columbian South America. Am J Phys Anthropol 68: 495-498.

Salo WL, Aufderheide AC, Buikstra J, Holcomb T 1994. Identification of Mycobacterium tuberculosis DNA in anancient mummy. Proc Natl Acad Sci USA 91: 2091-2094.

Schofield CJ 1994 Triatominae. Biología y Control. West Sussex, UK. Eurocommunica Publications: 1-79.

Schofield CJ, Matthews JNS 1985. Theoretical approach to active dispersal and colonization of houses by Triatoma infestans. J Trop Med Hyg 88: 211-222. 